cupy the entire tropical ocean in 2100 . However, when related to the column integrated heating, the area of the "dynamic warm pool" remained almost unchanged as it is determined by the SST gradient.

Combined data and modeling were used to address monsoon-related hydrological processes, e.g., to demonstrate how monsoon and deserts coexist as twin features of multi-scale forcing (G. Wu). Vegetation feedback modeling simulated that afforestation in monsoon regions cools summers, warms winters and increases spring-summer precipitation locally, but can affect remote climate into an opposite direction (Z. Liu). The use of transient climate simulation in Africa successfully simulated the abrupt start of the African Humid Period in the Sahel and revealed its connection with North Atlantic climate (B. Otto-Bliesner).

The Symposium covered the full range of timescales. Solar cycles, for example, were suggested to have direct and indirect effects on monsoon variations at multi-decadal and centennial timescales (J. Nott; W. Soon), while on centennial timescales the GM strength seems to respond more to the effective solar forcing (J. Liu). Monsoon records from Asia, Africa, and South America could be correlated globally (R. Tada; R. Schneider; F. Cruz; L. Peterson) and compiled oxygen isotope sequences of stalagmites from Asia and South America reveal anti-phasing on orbital, millennial and centennial timescales (H. Cheng; Fig. 1). This provides strong evidence that the GM is connected across hemispheres by the seasonal migration of the ITCZ in response to asymmetrical heat budgets. Global correlation of monsoon records enables us to indentify specific regional features, as demonstrated by the distinct response of the African and Indian monsoons to fresh water flux and ice-sheet forcing during the last glacial ( $P$. Braconnot). On tectonic timescales, steepening of tropical zonal and meridional SST gradients was called upon to explain the aridification of Africa from 2.8-1.6 Ma (P. deMenocal), coherent with the abovementioned monsoon-desert coupling.

Interesting discussions unfolded over monsoon proxies. The hydrogen isotope ratio of fossilized plant wax lipids from marine sediments was presented as an indicator of monsoon precipitation (R. Schneider). Several proxies were proposed to reflect the global monsoon intensity on longer timescales, including inorganic marine carbon isotopes (eccentricity cycles in ocean carbon reservoir), atmospheric methane concentration (tropical wetland extent) and oxygen isotopes of ice-trapped air (Dole effect). The similarity between oxygen isotope records from stalagmites and marine planktonic carbonate in monsoon regions provoked the question whether the oxygen isotope composition of the rainwater had fluctuated together with the GM intensity (P. Wang).

Extreme hydrological events were the final topic of the symposium. A variety of approaches, including sedimentological, geomorphological and isotopic, were introduced to study floods, droughts, and cyclones over the last millennia in Australia and India. Increases in flood frequency were found over the last century, suggesting coherence in the long-term history of the Australia-Asia Monsoon (V. Kale; E. Valentine and B. Wasson).

In summary, the symposium provided not just a global view of regional monsoons, but also a new perspective of the regional monsoons as part of a global system. Just as the high-latitude processes are centered around the poles, so are the low-latitudes processes, represented by monsoon and ENSO, centered at the climatic equator, i.e., the ITCZ. The GM responds directly to external forcing and is modulated by high latitude processes through teleconnections. The next step of the PAGES Global Monsoon Working Group will be a Special Issue of Climate Dynamics followed by a synthesis paper.

\section{References}

Berger, A.L., 1978: Long-term variations of caloric insolation resulting from the Earth's orbital elements, Quaternary Research, 9: 139167.

Dykoski, C.A., et al 2005: A high-resolution, absolute-dated Holocene and deglacial Asian monsoon record from Dongge Cave, China, Earth and Planetary Science Letters, 233: 71-86.

Wang, Y.J., Cheng, H., Edwards, R.L., An, Z.S., Wu, J.Y., Shen, C.C. and Dorale, J.A., 2001: A high-Resolution Absolute-Dated Late Pleistocene Monsoon Record from Hulu Cave, China, Science, 294 2345-2348.

Wang, Y.J., et al., 2008: Millennial-and orbital-scale changes in the East Asian monsoon over the past 224,000 years, Nature, 451 1090-1093.

Cruz, F.W., Burns, S.J., Karmann, I., Sharp, W.D., Vuille, M., Cardoso, A.O., Ferrari, J.A., Dias, P.L.S. and Viana Jr., 0., 2005: Insolation-driven changes in atmospheric circulation over the past 116,000 years in subtropical Brazil, Nature, 434: 63-66.

\title{
Relative sea level, ice sheets and isostasy past, present and future: P A L S E A Understanding the implications for human populations
}

\section{$3^{\text {rd }}$ PALSEA Workshop, Bristol, UK, 20-24 September 2010}

\author{
Morten B. Andersen and Mark Siddall \\ Department of Earth Sciences, University of Bristol, UK; mark.siddall@bristol.ac.uk
}

The joint PAGES-IMAGES Working Group "PALSEA" (Paleo-constraints on sea-level rise; www.climate.unibe.ch/ siddall/ working_group.html) aims to obtain information on climate and sea-level change during the Quaternary period with a multi-disciplinary approach. A better understanding of the relationship between climate, ice-sheet dynamics and sea level is critical for projections of future sea level rise expected from global warming and cannot be achieved using the instrumen- tal record alone. The $3^{\text {rd }}$ PALSEA workshop Relative sea level, ice sheets and isostasy past, present and future (understanding the implications for human populations) was held at University of Bristol.

The workshop was internationally attended by 80 participators from a wide range of sea-level related research areas including ice sheet and climate modelers, geophysicists with expertise in glacial-isostatic adjustment, field scientists engaged in reconstruction of ice-sheet extent and relative sea levels, and marine archeologists. Support was provided by PAGES, IMAGES, the Worldwide Universities Network, UK-Integrated Ocean Drilling Program and the University of Bristol. Scientific presentations and discussions were organized into broad themes of: (1) Predicting future sea-level and ice-sheet evolution (2) Sea level and ice sheets during Termination I (3) Ice sheets: observation and modeling (4) Sea level and ice sheets entering and during warm periods 


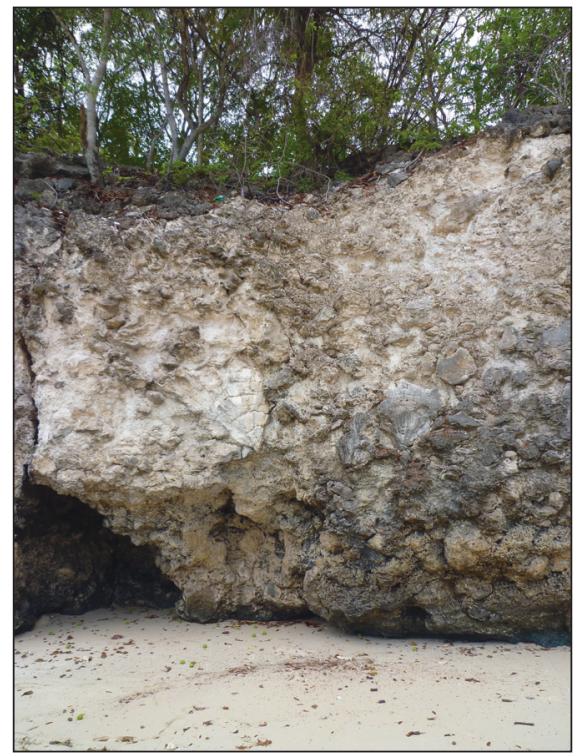

Figure 1: Fossil coral reefs, here from Barbados, are an important archive for reconstructing paleo sea level. Using fossil corals at different localities to reconstruct the deglacial sea-level rise during Termination I are key for determining melt water pulse events and the fingerprinting of sources of the ice-sheet melting (e.g. Antarctica vs. Northern Hemisphere)

(5) Sea levels and ice sheets during the Holocene (6) panel discussions focused on deliverables and future funding strategies.

Among the variety of topics discussed was sea level and ice-sheet evolution following Termination I, including comparisons of records of the last deglacial sea-level rise (e.g., from Sunda shelf and Tahiti corals) and meltwater pulse events
(MWP). Specific attention was given to the character of the MWP $1 \mathrm{~b}$ event, which was suggested to have been very small (if it existed at all) to be consistent with near field data. Ideally, a combination of existing and new observable data on MWPs, with well-defined error estimates, coupled with glacio-isotstatic adjustment (GIA) modeling would help to quantify MWPs more accurately, which is key to the understanding of ice-sheet extent and dynamics. For example, for MWP $1 \mathrm{a}$, there is a discrepancy between glaciological data and glacio-eustatic modeling on where the melt water was sourced (Antarctica, Northern Hemisphere or both). In order to address this problem, improved crossdisciplinary communication between data and model specialists is essential. Another important topic addressed was the stability of ice sheets during warm periods and in particular over the last 2000 years. Despite considerable attention, there remain many unanswered questions, particularly concerning sea level and ice-volume stability in relation to insolation forcing during warm periods. Research on ice-sheet stability during present and past warm climates will benefit our general understanding of ice-sheet dynamics of both the Antarctic and Greenland ice sheets. Improved sea level estimates for the Pliocene Warm Period (when ice sheets were
1) We continue to work towards a global, open source and quality monitored database of RSL and ice-sheet extent

2) We support efforts to generate new RSL and ice-sheet extent records and improve techniques.

3) We support efforts in glacio-isostatic adjustment (GIA) and ice-sheet model intercomparison and aspire to the creation of community GIA models in line with other modeling communities.

4) We emphasize the critical importance of close working relationships between climate modelers, ice sheet modelers, GIA modelers and field scientists who study RSL and ice-sheet extent on a variety of timescales.

Table 1: $3^{\text {rd }}$ PALSEA Workshop statements. These statements form the core framework for the continuing effort of the PALSEA workgroup.

greatly reduced), provides another way to address this issue and will be the focus of further research within the PLIOMAX project (Raymo et al., 2009).

Because the main focus points of the PALSEA Working Group is to tightly integrate the different communities working on research themes related to reconstruct past and predict future sea-level fluctuations, a set of key workshop statements was formulated (Table 1).

\section{References}

Raymo, M.E., Hearty, P., De Conto, R., O'Leary, M., Dowsett, H.J., Robinson, M.M. and Mitrovica, J.X., 2009: PLIOMAX: Pliocene maximum sea level project, PAGES news, 17(2): 58-59.

\title{
Learning from other communities:
} Towards more robust varve chronologies

\section{$2^{\text {nd }}$ workshop of the PAGES Varves Working Group, Corpus Christi, USA, 17-19 March 2011}

\author{
Mark Besonen ${ }^{1}$, P. Francus ${ }^{2}$, A.E.K. OJala ${ }^{3}$, R. Behl ${ }^{4}$ and B. Zolitschka ${ }^{5}$
}

${ }^{1}$ Texas A\&M University-Corpus Christi, USA; mark.besonen@tamucc.edu

${ }^{2}$ National Institute of Scientific Research, Québec, Canada; ${ }^{3}$ Geological Survey of Finland, Espoo; ${ }^{4}$ California State University, Long Beach, USA;

5University of Bremen, Germany

Varved sediment records, i.e., sediment records that accumulate in discrete annual to sub-annual increments, archive an extremely rich variety of paleo information either via their simple physical sedimentology, or from the chemical, isotopic or biological proxies they may contain. Despite this richness, these records are only sparsely used in regional and global climate reconstructions, which tend to favor other annually resolved records such as tree rings. Against this backdrop, and a decade long gap without any large meeting of the varve community, the PAGES Varves Working Group (VWG) was established in 2010. The VWG held a productive first workshop in Tallinn, Estonia in April 2010 that focused on reviewing methodological advances in varved sediment studies over the last decade (Francus et al., 2010; Ojala and Kosonen, 2010). In order to expand the reach of the VWG, recognition by INQUA was recently petitioned, and the VWG was granted project status as "INQUA Project Number 1102-VWG Project".

A second workshop was held in March 2011 on the campus of Texas A\&M University-Corpus Christi, USA. A scientific program and abstract volume is posted on the project's website www.pages-igbp. org/workinggroups/varves-wg/. This second workshop focused on the develop- ment of more robust varve chronologies based on what could be learned from the communities that work with other nonsedimentary annually resolved climate archives. It was attended by 31 scientists from institutions in 10 different countries. Early career scientists, such as graduate students, post-docs and new faculty, accounted for nearly half of the participants (14 of the 31); thus, the workshop provided a great opportunity for knowledge transfer from more experienced varve researchers to young academics.

The three-day workshop began with a review of sediment varve chronologies (a task that will form the basis of one of 